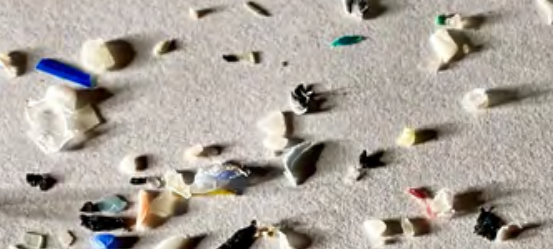

\title{
Microplastics in the Delaware River, Northeastern United States
}

\section{What are microplastics and where do they come from?}

Microplastics are a contaminant of increasing concern in aquatic environments. Our understanding of microplastics in freshwater environments has increased dramatically over the past decade, but we still lack information on microplastic occurrence and biological uptake in National Park Service (NPS) waters. Defined as plastic particles less than 5 millimeters $(\mathrm{mm})$ in diameter, microplastics come from a wide variety of sources (see "Microplastic types and possible sources" infographic) and commonly are classified by particle type or morphology, including fibers, pellets/beads, foams, films, fragments, and tire particles. Microplastics reach aquatic environments through diverse pathways, including littering, stormwater runoff, industrial and domestic wastewater, overland application of biosolids, atmospheric deposition, and breakdown of aquatic equipment such as buoys and boats.

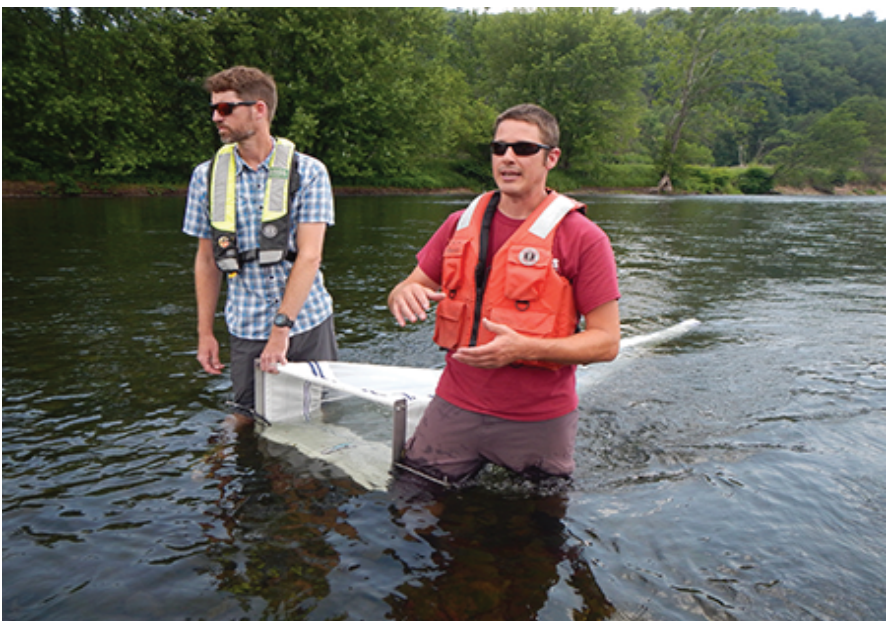

Figure 1. U.S. Geological Survey scientists collecting a microplastics sample in the Delaware River at Callicoon, New York.

\section{Microplastic types and possible sources}

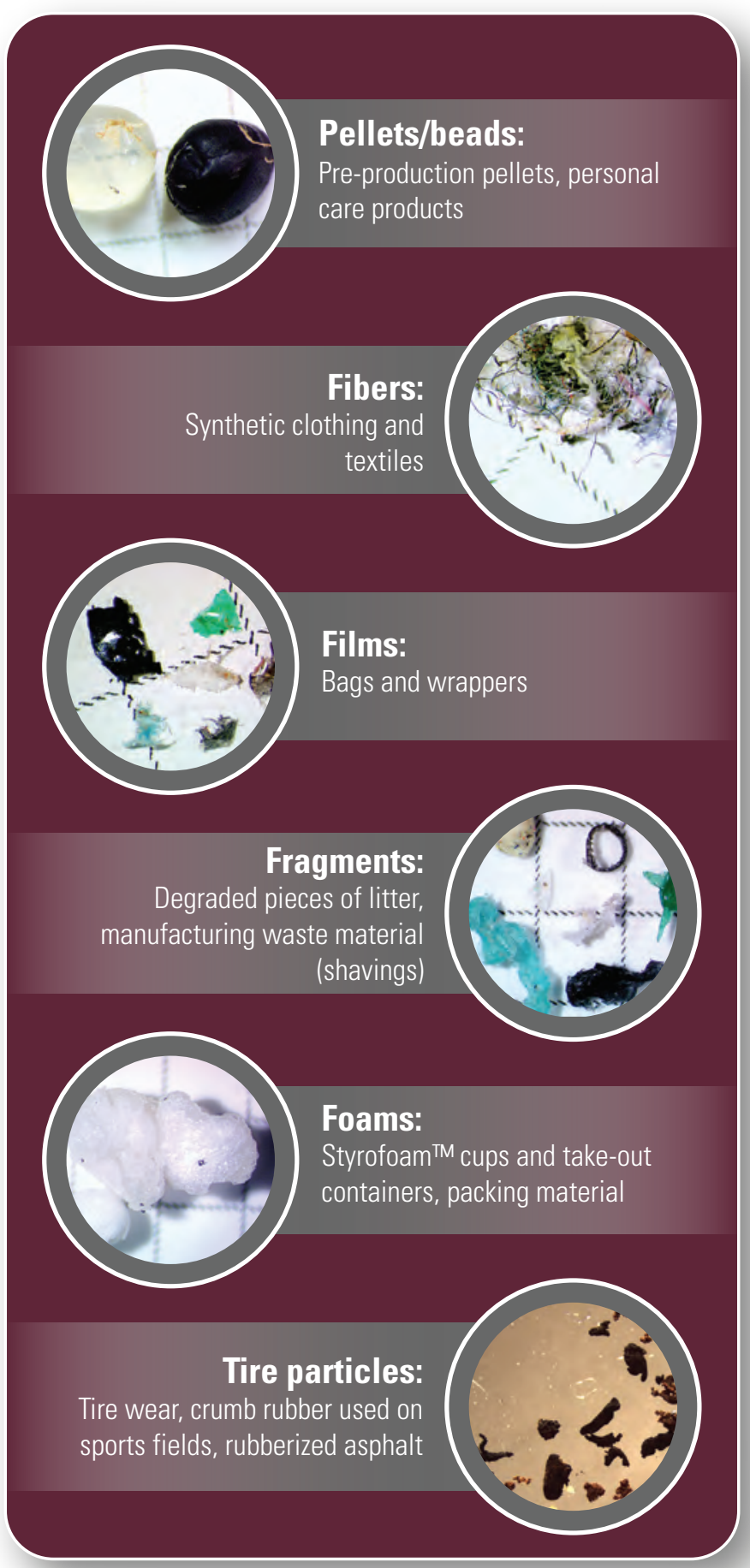




\section{Biological ingestion and effects}

Once in the environment, microplastics continue to break down into smaller and smaller particles through mechanical and chemical weathering, eventually reaching nano-scale. This continuous breakdown results in a broad range of particle sizes, enabling organisms across the food web-from mammals and birds to fish and zooplankton - to ingest microplastics. The biological effects of ingestion are poorly understood, but they can include reproductive effects, oxidative stress, toxicity to the liver, and cellular damage, among other effects (Rochman and others, 2016).

\section{Delaware River microplastic sampling efforts}

During 2015-19, the U.S. Geological Survey (USGS) and the NPS conducted a three-phase study of microplastic occurrence and biological uptake in NPS waters. Phases 1 and 2 focused on the St. Croix National Scenic Riverway, the Mississippi National River and Recreation Area, and Lake Mead National Recreation Area (Baldwin and others, 2017; Baldwin and others, 2020a). This Fact Sheet summarizes results from Phase 3 in which microplastics were sampled at nine locations spanning various land uses on the Upper Delaware, Middle Delaware, and Lower Delaware Scenic and Recreational River and its tributaries (figs. 1 and 2; table 1; Baldwin and others, 2020b). Water and sediment samples were collected during baseflow conditions at each location. To assess potential biological uptake of microplastics, fish and mussels were collected at a subset of locations. Fish were pelagic-feeding smallmouth bass (Micropterus dolomieu) and benthic-feeding white sucker (Catostomus commersonii), and mussels were eastern elliptio (Elliptio complanata). Microplastic particles were sorted by size $(0.35-1.0 \mathrm{~mm}$ and $1.0-5.6 \mathrm{~mm}$ for water and sediment samples; 0.125-5.6 mm for fish and mussel samples), counted, and grouped into one of six categories: fibers, pellets/beads, foams, films, fragments, and tire particles. Detailed methods and all results are available online as a USGS data release at https://doi.org/ 10.5066/P9QVIVX3 (Baldwin and others, 2020b).

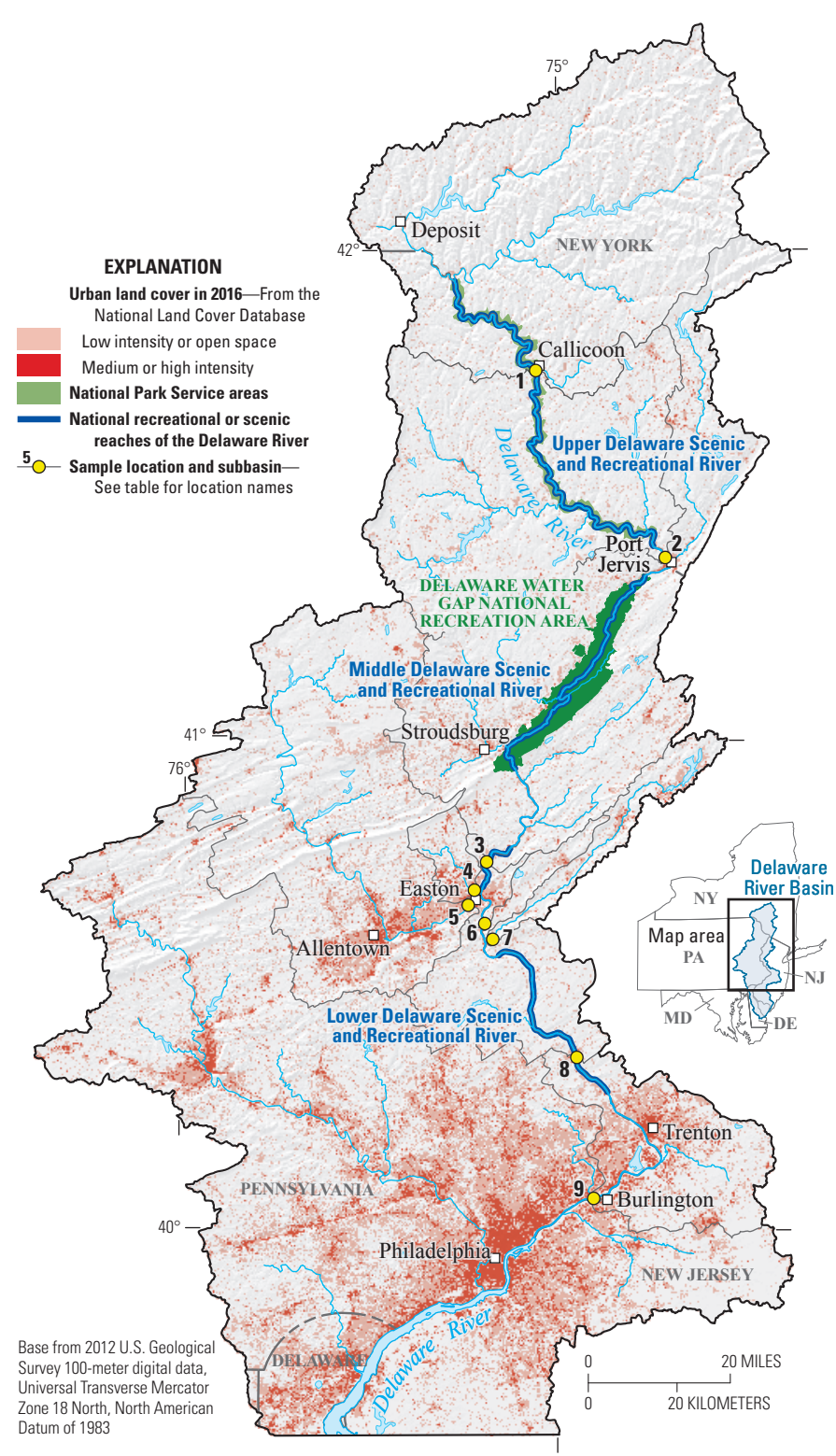

Figure 2. Microplastic sampling locations on the Delaware River and select tributaries, Northeastern United States.

Table 1. Microplastic sampling locations, watershed characteristics, and numbers of samples collected, Northeastern United States.

[Map identifiers are shown in figure 2. N.J., New Jersey; N.Y., New York; Pa., Pennsylvania]

\begin{tabular}{|c|c|c|c|c|c|c|c|}
\hline \multirow{2}{*}{$\begin{array}{l}\text { Map identi- } \\
\quad \text { fier }\end{array}$} & \multirow{2}{*}{ Site name } & \multicolumn{2}{|c|}{ Land cover (percent) } & \multicolumn{4}{|c|}{ Number of samples } \\
\hline & & Urban & Agriculture & Water & Sediment & Fish & Mussels \\
\hline 1 & Delaware River at Callicoon, N.Y. & 4.5 & 11 & 1 & 1 & 0 & 6 \\
\hline 2 & Delaware River at Port Jervis, N.Y. & 5.7 & 10 & 1 & 1 & 0 & 0 \\
\hline 3 & Delaware River at Sandts Eddy, Pa. & 7.5 & 10 & 1 & 1 & 8 & 8 \\
\hline 4 & Bushkill Creek at Easton, Pa. & 33 & 37 & 1 & 1 & 0 & 0 \\
\hline 5 & Lehigh River at Glendon, $\mathrm{Pa}$. & 20 & 16 & 1 & 1 & 0 & 0 \\
\hline 6 & Delaware River at Raubsville, $\mathrm{Pa}$. & 11 & 12 & 1 & 1 & 0 & 0 \\
\hline 7 & Musconetcong River at Riegelsville, N.J. & 19 & 17 & 1 & 1 & 0 & 0 \\
\hline 8 & Delaware River at Lambertville, N.J. & 11 & 13 & 1 & 1 & 8 & 8 \\
\hline 9 & Delaware River at Burlington, N.J. & 13 & 14 & 1 & 1 & 0 & 0 \\
\hline
\end{tabular}




\section{Delaware River microplastic sampling results}

Microplastics were found in 100 percent of water and sediment samples, 94 percent of fish, and 45 percent of mussels (figs. 3 and 4; Baldwin and others, 2020b). Fibers were dominant across all sample types, constituting 70 percent of microplastics in water samples, 77 percent of microplastics in sediment samples, 97 percent of microplastics in fish samples, and 100 percent of microplastics in mussel samples (fig. 5; Baldwin and others, 2020b). Previous studies in other NPS locations have reported a similar predominance of fibers across sample types
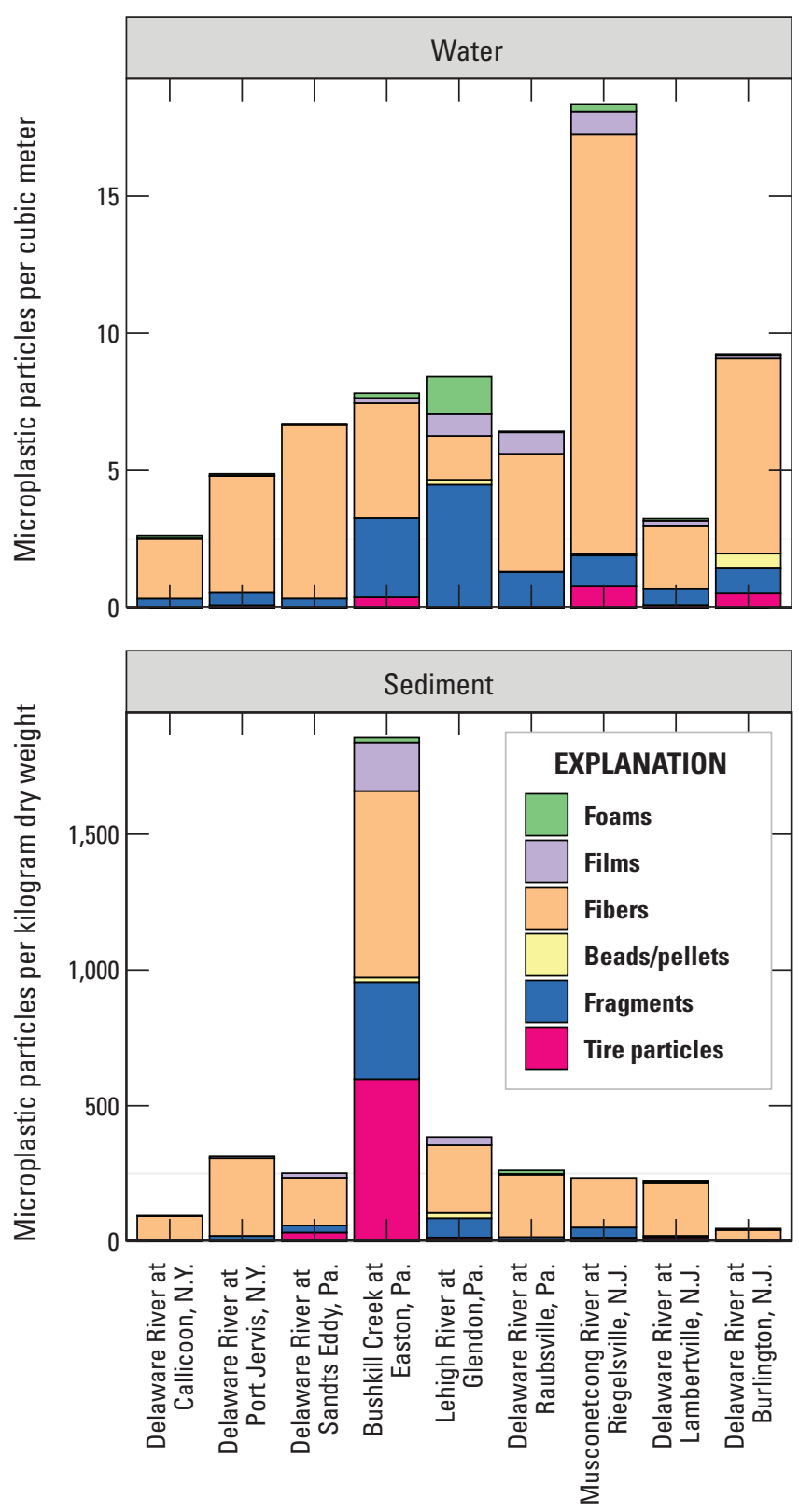

Sampling locations

Upstream $\longrightarrow$ Downstream

Figure 3. Microplastic concentrations in water and sediment samples from locations on the Delaware River and selected tributaries, Northeastern United States.

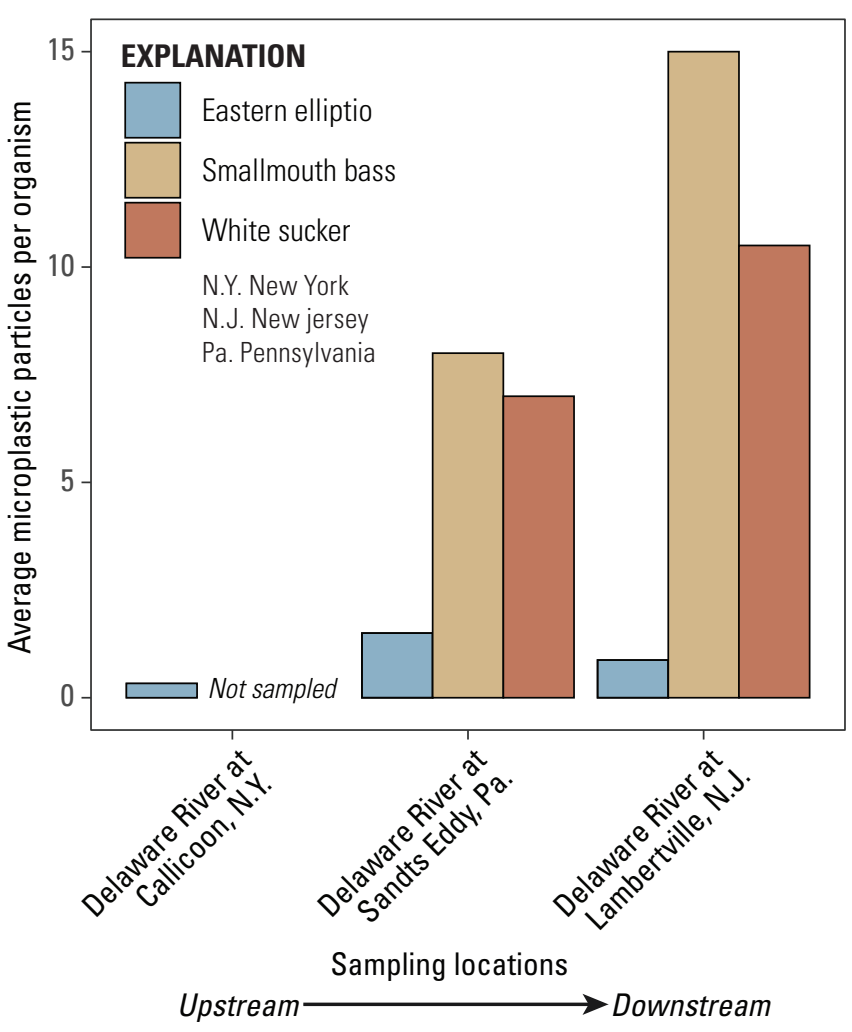

Figure 4. Average microplastic concentrations in mussels (eastern elliptio) and fish (smallmouth bass and white sucker) from select locations on the Delaware River, Northeastern United States. Numbers of samples are provided in table 1.

(Baldwin and others, 2017, 2020a). Microplastic concentrations averaged 7.5 particles per cubic meter in water samples (maximum 18.3 particles per cubic meter), 405 particles per kilogram of dry weight in sediment samples (maximum 1,840 particles per kilogram of dry weight), 10.1 particles per organism in fish (maximum 28 particles per organism), and 1.0 particles per organism in mussels (maximum 5 particles per organism).

The highest concentration in water samples was from the Musconetcong River, a watershed with a relatively high percentage of urban land cover (19 percent; table 1; Baldwin and others, 2020b). The highest concentration in sediment samples was from Bushkill Creek, the most urban watershed (33 percent urban; table 1). The Bushkill Creek sediment sample was unique in its high concentration and high proportion of tire particles (598 particles per kilogram of dry weight, 33 percent of all microplastic particles, respectively). Tire particles, whose leachate has been shown to be toxic to some fish species (Tian and others, 2020), have been reported at similar concentrations in streambed sediment in other urban watersheds (Lenaker and others, 2019) and may come from tire wear, crumb rubber (sports fields, playgrounds), and rubberized asphalt, among other sources. The lowest concentration in water samples was from the Delaware River at Callicoon, the site with the least urban watershed. The lowest concentration in sediment samples was from the Delaware River at Burlington. 

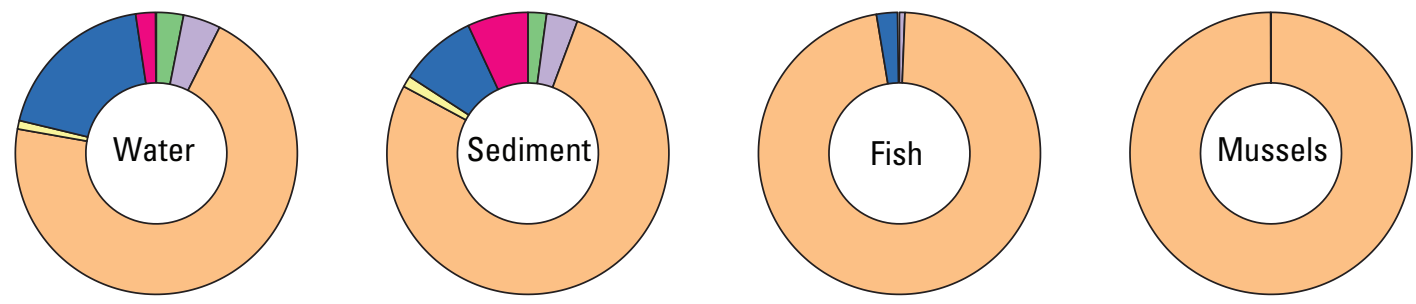

Figure 5. Overall percentages of microplastic particles in each type of sample on the Delaware River, Northeastern United States.

Smaller microplastics $(0.35-1.0 \mathrm{~mm})$ were 4.6 times more abundant than larger microplastics $(1.0-5.6 \mathrm{~mm})$ in water samples, and 2.4 times more abundant than larger microplastics in sediment samples. Microplastics in fish and mussels were not sorted by size.

In summary, microplastics are not only present in NPS-managed sections of the Delaware River, but they are being ingested by aquatic organisms. Although the Baldwin and others (2020b) study did not examine the biological effects of microplastic ingestion on aquatic organisms, previous studies have shown lethal and sublethal effects (Rochman and others, 2016). Future research may help us better understand (1) the sources and pathways of microplastics to the Delaware River, (2) the occurrence of smaller $(<0.35-\mathrm{mm})$ microplastics and nanoplastics that were not included in the Baldwin and others (2020b) study but biologically may be equally or more relevant, and (3) the potential effects of microplastics on individual species and the ecosystem.

\section{References Cited}

Baldwin, A.K., King, K., Damstra, R., Karns, B., Weller, L., Mason, S.A., Hoellein, T.J., and Kim, L.H., 2017, Microplastics are everywhere! National Park Service Resource Brief, p. 1-4.

Baldwin, A.K., Spanjer, A.R., Hayhurst, B., and Hamilton, D., 2020b, Microplastics in the Delaware River, 2018: U.S. Geological Survey data release, https://doi.org/ 10.5066/P9QVIVX3.
Baldwin, A.K., Spanjer, A.R., Rosen, M.R., and Thom, T., 2020a, Microplastics in Lake Mead National Recreation Area, USA-Occurrence and biological uptake: PLoS One, v. 15, no. 5, p. e0228896.

Lenaker, P.L., Baldwin, A.K., Corsi, S.R., Mason, S.A., Reneau, P.C., and Scott, J.W., 2019, Vertical distribution of microplastics in the water column and surficial sediment from the Milwaukee River Basin to Lake Michigan: Environmental Science \& Technology, v. 53, no. 21, p. 12227-12237.

Rochman, C.M., Browne, M.A., Underwood, A.J., van Franeker, J.A., Thompson, R.C., and Amaral-Zettler, L.A., 2016, The ecological impacts of marine debris-Unraveling the demonstrated evidence from what is perceived: Ecology, v. 97 , no. 2 , p. 302-312.

Tian, Z., Zhao, H., Peter, K.T., Gonzalez, M., Wetzel, J., Wu, C., Hu, X., Prat, J., Mudrock, E., Hettinger, R., Cortina, A.E., Biswas, R.G., Kock, F.V.C., Soong, R., and others, 2020, A ubiquitous tire rubber-derived chemical induces acute mortality in coho salmon: Science, doi:10.1126/science.abd6951, accessed December 4, 2020, at https://science.sciencemag.org/content/early/2020/12/09/ science.abd6951.

\section{Authors:}

Austin K. Baldwin, Andrew R. Spanjer, and Brett Hayhurst (U.S. Geological Survey); and Donald Hamilton (National Park Service)

For more information:

USGS National Water Quality Program

https://www.usgs.gov/water-resources/national-water-quality-program 1-800-ASK-USGS (1-888-275-8747)

Photograph credits:

USGS employees in stream, Donald Hamilton. Banner image, Andrew Spanjer.

Publishing support provided by the U.S. Geological Survey Science Publishing Network, Tacoma Publishing Service Center Design: Yanis X. Castillo

Any use of trade, firm, or product names is for descriptive purposes only and does not imply endorsement by the U.S. Government. 